\title{
An exploratory study on Indigenous Knowledge of 'Green Technology' (IKGT) among orang asli in Malaysia
}

\author{
Regina Lambin ${ }^{1 *}$, Norwaliza Abdul Wahab ${ }^{2}$, Goh Swee Choo ${ }^{3}$, Ramlee Mustapha ${ }^{4}$, \\ Ramlee Abdullah ${ }^{5}$ \\ 1, 2, 3 Faculty of Human Development, Universiti Pendidikan Sultan Idris, Tanjung Malim, Malaysia \\ ${ }^{4}$ Faculty of Technical and Vocational Education, Universiti Pendidikan Sultan Idris, Tanjung Malim, Malaysia \\ ${ }^{5}$ Faculty of General Study and Continuing Education, Universiti Sultan Zainal Abidin, Terengganu, Malaysia
}

\section{Keywords}

Orang asli

Green technology

Indigenous knowledge

Indigenous medicine

Indigenous handicraft

Received: 12 June 2018

Accepted: 11 July 2018

Published: 9 August 2018

\begin{abstract}
This study aims to examine the use of Orang Asli indigenous knowledge of their 'green technology' to practice environmental sustainability and conserve natural resources now and later on to make the earth 'greener.' The study employed a descriptive case study qualitative approach which used in-depth interview, field observation, and document analysis as an exploration instrument. The design of the conceptual framework was framed based on two themes; Indigenous Medicine (IM) and Indigenous Handicraft (IH). This research was carried out at Orang Asli settlements in 4 states: i) Selangor, ii) Perak, iii) Terengganu, and iv) Pahang, which involved six informants aged 30 and older. The study's findings will be valuable for sharing Orang Asli IKGT and providing the main strategies in which the benefits of utilizing their green practices in the future world would outweigh its cost. Orang Asli IKGT's framework can be used by the current society as a guide to lessen carbon footprint and others harm evolved. In addition, it serves as a basic or medium for all levels; institutional, regional, national, and local scales aspire to launch sustainability programs locally or internationally and expand economic and market forces while safeguarding cultural diversity.
\end{abstract}

(C) 2018 The Author(s). Published by TAF Publishing.

\section{INTRODUCTION}

Nowadays, the problem of limited resources depletion increases along with the preservation of the Earth. Eyong, Mufuaya, and Foy (2004) claim that the Earth is so polluted to the point that the specific survival of mankind is threatened as evidenced by silent emergencies such as desertification, deforestation, fast degradation of motherland due to abusive and improper utilization of fertilizers, polluted rivers, air and soil caused by industrial effluents. There are numerous scientific phenomena which show that the Earth's atmosphere has changed throughout the years. According to National Oceanic and Atmospheric Administration (NOAA), it is worth researching on the expanding of worldwide temperature as it is one component of observed global climate change. The rise of the world's surface temperature has brought worldwide concern and is presently comprehended as one of the vital challenges confronted by human being (Lee, Kim, \& Jeon, 2016; Makkar, 2013). The biggest challenge the world needs to deal with is global warming but till date, the solution for this crisis in shielding our common future stay insufficient. The concern specified in Figure 1 as below illustrates the time series of the five-year average variation of global surface temperature. This demonstrates the surface of the Earth is becoming increasingly threatened and the temperature increase over the years from $-0.28^{\circ} \mathrm{C}$ in 1884 to $0.99^{\circ} \mathrm{C}$ in 2016 (National Aeronautics and Space Administration, 2018). Climate change, global warming and increased Earth's surface tem-

\footnotetext{
*corresponding author: Regina Lambin

†email: geenalambin@gmail.com
} 
perature will give huge impacts to the nature around the globe and will speed up the process of biodiversity loss. Modern technology poses a serious threat to sustainable development due to their harmful effects on natural resources and the environment (Eyong, 2007). In addition, modern technology destroys the habitats of wildlife. Environmental degradation and the lessening of resources affect everyone in the long term. The implication is that over-exploitation and other forms of biodiversity loss threaten cultural diversity (Frid, McGreer, Haggarty, Beaumont, \& Gregr, 2016;
Poe, Norman, \& Levin, 2014; Sangha, Le Brocque, Costanza, \& Cadet-James, 2015; Turner, Ignace, \& Ignace, 2000). The life-support system of the Earth can be compared to a boat; any spillage on one part of this boat will influence the whole boat and not just the affected part. The issues such as global warming, ozone depletion, energy wastage, and pollution have alarmed the housing and construction industry to implement sustainable and green solutions (Victoria et al., 2017).

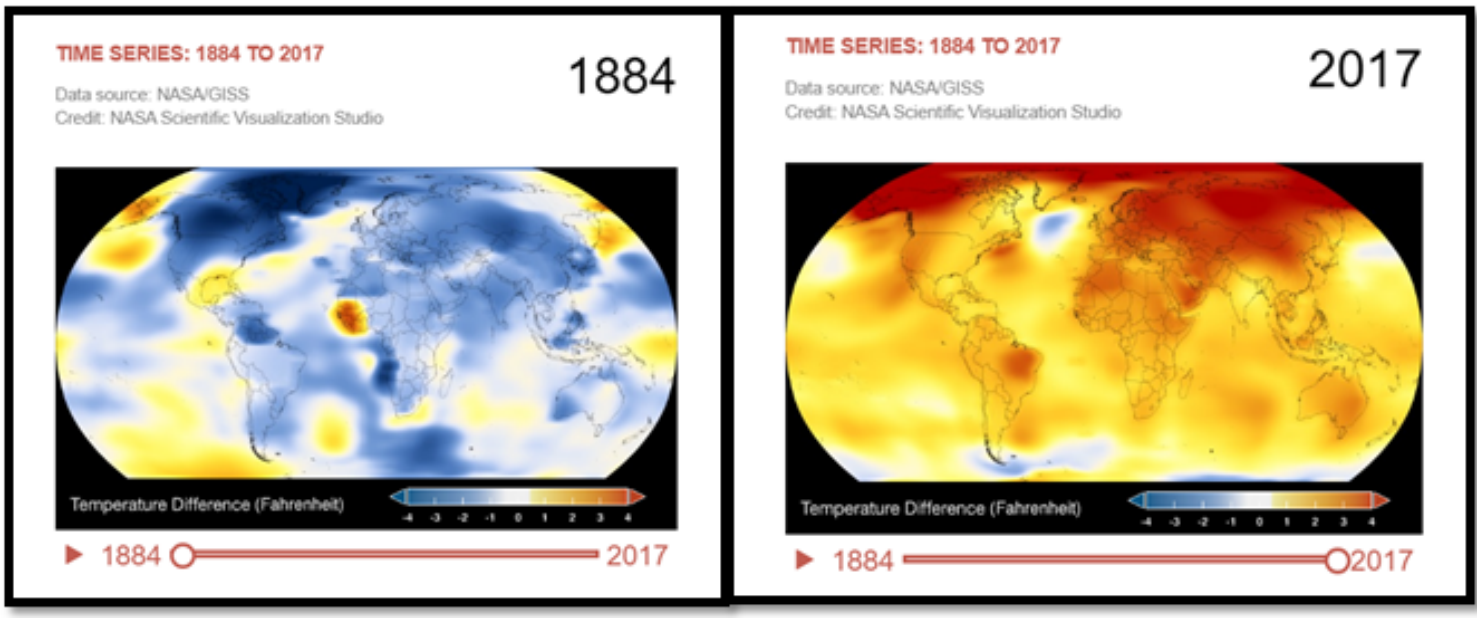

FIGURE 1. Global surface temperature (Time Series 1884-2017 Source: NASA/GISS (2018) )

As indicated by the United Nation (2007), most of the world's remaining natural resources - minerals, freshwater, potential vitality sources and more are found in indigenous zones. The best way to reduce the damaging effects is to improve the basic knowledge of the indigenous groups and to encourage Orang Asli to sustain, maintain and manage their natural resources while strengthening their Indigenous Knowledge (IK). As referred to the study conducted by Robinson and Herbert (2001), they emphasized that incorporating IK into climate-change policies can lead to the development of effective strategies adoption that is cost-effective, participatory-friendly and sustainable. However, in these modern days of technology advancement, Orang Asli IK is in mortal danger, and it is often forgotten or neglected. This is due to the widespread of external opportunistic interest, causing Orang Asli to be dispossessed from their traditional territories or had their traditional environments degraded by others. The study conducted by Boyer (2011) emphasizes that the environmental impact of industrialization constitutes a brutal assault on Orang Asli's wellbeing and continues the harms of colonization. Parsons, Nalau, and Fisher (2017) also state that the efforts of integrating IK and Western science often encounter problems due to different systems of knowledge production and underlying worldviews. Therefore, the indigenous communities persist in maintaining their unique worldviews and systems of knowledge associated with them in facing the social transformation, colonization, displacement and forced integration (Augare et al., 2017; Cherdchoongam \& Rungreunganun, 2015.).

Hence, this study intends to preserve Indigenous Knowledge of 'Green Technology' (IKGT) and the practices of a several of natural biological resources such as IM and IH and study on how such pieces of knowledge can add value to the overall conservation and sustainable development of natural habitats and ecosystems. It also aims to explore the IK and wisdom of $\mathrm{OA}$ in solving their daily problems by utilizing 'Green Technology (GT)' to conserve and provide invaluable knowledge and aid in making the best use of natural sources that can be utilized by present societies. Specifically, the objectives of this study are;

I. To clarify the epistemology of Orang Asli IKGT on IM and IH.

II. To identify the IKGT and green practices used by Orang Asli on IM and IH.

This study will be valuable for the purpose of sharing new 
knowledge regarding Orang Asli IKGT, particularly in IM and IH. This can be significant as this research confirmed that orang Asli IKGT contributed to the information systems solution in preserving environmental sustainability. This study is directly relevant to green practice as its data are about the preservation and sustainability environment based on orang Asli IKGT. This study is also prominent to identify Orang Asli IKGT which is increasingly less known, learned and practiced by the younger generation of Orang Asli. Their IKGT used in combating global warming, climate change, and ozone depletion contributes to the information systems solutions in preserving or conserving environmental sustainability. Also, this study provided the main strategies by which the benefits of using Orang Asli IKGT in the future world would overweight its cost.

The contribution of Orang Asli IKGT on IH and IM can play a big role in combating the global ecological crisis. In 2017, Grobar emphasized that handicraft production has played an important role in many developing countries and highlights that the preservation and promotion of cultural and artistic traditions, as numerous abilities involved in the production of traditional products, have been inherited from era to era. Not only that, the findings of the research results may contribute as a source or reference for further studies about Orang Asli tribes, particularly in their expertise in IKGT and green practices. In addition, this study is also essential to be documented as it has potential to expand and strengthen Orang Asli IKGT since this valuable and precious knowledge is in mortal danger and it is often forgotten or neglected due to modernization, deforestation, and globalization. This statement was supported by the study conducted by Lambin, Wahab, Choo, Mustapha, and Abdullah (2018a), which emphasized that is a need to document and preserve IK in medicinal plants for future prospective and generations before this knowledge weakened or vanishes.

\section{LITERATURE REVIEW Orang Asli}

'Orang Asli' is a Malay term which literally means 'original people' or 'first people' Masron, Masami, and Ismail (2013) and is also known as the original people of the Peninsular Malaysia (Ahmad, Khalid, Quek, Zaini, \& Phipps, 2013). The term "indigenous people" is in itself a challenging classification of individuals and alludes to "culturally particular ethnic groups with a different character from the national society, draw presence from local asset and are politically nonprevailing (Melchias, 2001). According to Act 134, Aboriginal Peoples Act 1954 under the Aboriginal People Ordinance No. 3 which was reviewed in 1974, Orang Asli is defined as any of which the father is a member of the Orang Asli tribes, who speaks Orang Asli languages and follows the way of life, beliefs and traditions of Orang Asli's including the descent through the man (Jabatan Kemajuan Orang Asli Malaysia, 2017).

There is a large number of published studies such as (Carey, 1976; Dentan, 1968; Lambin, Wahab, Choo, Mustapha, \& Abdullah, 2018b; Ong \& Azliza, 2015; Ong, Faezah, \& Milow, 2012; Mustapha, Omar, Hassan, Yasin, \& Salleh, 2010) which stated that Orang Asli can be divided into three ethnolinguistic groups, namely the Negrito (Semang), Senoi and Proto-Malay (Aboriginal Malay) with six different tribes in each main groups (Figure 1). These six different tribes which can be further sub-divided into 18 sub-tribes with their own physical characteristics, linguistic affinities, cultural practices (Ang et al., 2011; Bellwood, 1997; Hood, 2006; Nicholas, 1996) with unique features, lifestyles, and languages (Abdul Ghani Azmi, 2017).

TABLE 1. Orang asli ethnolinguistic group

\begin{tabular}{lll}
\hline \hline Senoi (55\%) & Proto-Malay (42\%) & Negrito (3\%) \\
\hline Che Wong & Semelai & Kensiu \\
Mah Meri & Jakun & Kintak \\
Jahut & Kanaq & Jahai \\
Semoq Beri & Kuala & Lanoh \\
Semai & Seletar & Mendriq \\
Temiar & Temuan & Bateq \\
\hline \hline
\end{tabular}

The Groups of Orang Asli in Peninsular Malaysia (Jabatan Kemajuan Orang Asli Malaysia, 2017)

Orang Asli is estimated to account for around $13.9 \%$ of the 31 million population in Peninsular Malaysia (International Work Group For Indigenous Affairs, 2017). The Senoi is the largest ethnic group constituting about $55 \%$ of the total population of Orang Asli, followed by the Proto-Malays and the Negritos at $42 \%$ and $3 \%$ respectively (Wahab, 
Mustapha, \& Ahmad, 2016). The sub-group of Senoi includes Mah Meri, Semoq Beri, Temiar, Che Wong, Jah Hut, and Semai. About 8000 years ago, few scholars identified that Senoi tribes have arrived in Peninsular Malaysia during the second wave of migration back from South Asia, the mountain areas of Cambodia, Vietnam and Burma (Ang et al., 2011; Baer, 1999; Nicholas, 1996; Thevakumar et al., 2016) and has a total population of about 60,000. In turn, they settled down in the area of Perak, Pahang, Kelantan, Selangor, and Terengganu (Fui, 1997; Ramlee, 2013). The Proto-Malay lives mainly in Selangor, Negeri Sembilan, Pahang, Melaka, and Johor. There are six sub-groups under Proto-Malay namely; Jakun, Temuan, Semelai, Orang Kuala, Orang Kanaq and Orang Seletar (Ang et al., 2011; Jabatan Kemajuan Orang Asli Malaysia, 2017). Negrito who is also referred as Semang consists of six sub-groups called Kensiu, Kintak, Jahai, Mendriq, Bateq, and Lanoh. According to Abdul Ghani Azmi (2017), the Negrito was believed to have arrived in Peninsular Malaysia between 10,000 and 60,000 years ago. This statement is supported by Edo and Fadzil (2004) Hamid, Samah, and Man (2013) who emphasize that the Negrito tribes are the oldest inhabitant of Peninsular Malaysia. Ismail et al. (2013) demonstrated that population screening was performed on 600 Negritos in three states of Malaysia including Kedah, Kelantan, and Perak from November 2005 until August 2009.

Nowadays, Orang Asli, the minority community in Peninsular Malaysia do not isolate themselves from contemporary culture and economy, yet maintain a tradition of interconnection with wild species. They own and practice a variety of custom cultures, taboos, beliefs, health practices and their unique or distinctive values whereby they emphasize harmonious living between human beings and their natural environment. The close relationship has greatly influenced the way of life and their economic resources (Sam \& Aminah, 2015). They possess unique and distinctive skills in managing the natural environment and are also rich with taboos in their daily life. To be sure, it is well known that Orang Asli safeguards and deals with their natural resources and the biological systems surrounding them for their survival (Hong, 1987). Orang Asli possesses some knowledge of transmitting the facts, ethics, wisdom, or lessons on flora and fauna. While their ancestors are communicating with nature, they observed and learned nature carefully on how to manage their resources and deal with severe situations (Lim, Mukrimah, Norliyana, \& Intan, 2017). Such knowledge which has been inherited from generation to generations is commonly called as IK.

\section{Indigenous Knowledge of 'Green Technology' (IKGT)}

The term 'IK' is employed to clarify the knowledge at intervals of a given community or society instead of the scientific knowledge that is normally alluded as 'modern' knowledge' (Ajibade, 2003). It is also normally understood as 'primitive knowledge' of Orang Asli. In general, IK can be a body of information, skill, and technology that belongs to a selected geographical community (Ndangwa, 2007; Macherera, Chimbari, \& Mukaratirwa, 2017) and is transmitted orally from generation to generation (Ebele, Anyaoku, Orizu, \& Eneh, 2015). The term IK has been outlined by various scholars, depending on their specialties and focus of study (Bloemfontein, 2009). According to Siyanbola, Egbetokun, Olamade, Aderemi, and Sanni (2012), IK is a specific commonality to be noted as IK is usually referred to the long-standing aged customs and practices of bound native or indigenous communities because of the wisdom, knowledge, and teachings of those tribes. In another context, IK is generally understood as the traditional knowledge, though there is a discussion regarding whether or not the term IK ought to be used interchangeably with the term traditional knowledge or whether or not it is more accurately understood as a set of traditional knowledge category (Nakata, Byrne, \& Gardiner, 2005). It is additionally referred to as the art of victimization of natural resources. The traditional knowledge has been passed on throughout different ages (though discriminatorily) and has empowered indigenous people to survive, deal with their natural resources and also the biological systems of their surroundings. Similarly, Eyong (2007) explains that IK practices are farmer-friendly, socially accepted, economical, environmentally-friendly, and suited to the particular native and environmental conditions. The term 'technology' refers to the appliance of information for viable functions. The sphere of 'green technology' envelops a perpetually evolving cluster of approaches and materials, from techniques for making vitality to non-toxic cleaning merchandise (Green Technology, 2015). Norizan, Hussin, and Hasimah (2017) stress that green technology is an application, instrumentation or system that has the characteristics of environmental property and is environmentally-friendly. This is supported by National Green Technology policy (Government Treasury, 2017) which states that green technology is the development and application of products, equipment, and systems for protecting the environment and nature and minimize or scale back the negative impact of the activities to a human being.

In this study, IKGT refers to the art of using natural resources that have been inherited orally from generation 
to generation while not damaging and depleting diverseness nor use harmful substances for future generation. It was developed through representational experimentations although these experiments were not documented and also the knowledge systems were legitimized and fortified below appropriate institutional frameworks, culture, and practices. IKGT practices might have some weaknesses, issues, and constraints, however, it must not be forgotten that they need to sustain under extreme conditions to support the local knowledge they possess. IKGT also embraces various aspects of 'primitive technology' which are naturalistic and environmentally-friendly. The knowledge facilitates people to reduce human impact on the environment and make ways for sustainable development. It additionally provides the basis for problem-solving ways to native communities, particularly the poor. Learning this will improve the understanding of native conditions and supply a productive context for activities designed to assist the communities toward understanding green technology with the hope to increase the responsiveness of their desires.

\section{METHODOLOGY}

The qualitative descriptive case study research design was employed for this study. The researcher employed two themes: i. Indigenous Medicine (IM) and ii. Indigenous Handicraft $(\mathrm{IH})$ as the guideline for the study. The study areas involved three tribal groups of Orang Asli that were conducted in 4 states; i) Selangor, ii) Perak, iii) Terengganu, and iv) Pahang of Peninsular Malaysia. The case study method of this study involved an in-depth analysis of the selected individuals based on the purpose to understand indepth and to induce a clearer picture concerning IKGT in the perspective of Orang Asli. Zainal (2007) states that the case study method enables an analyst to look at the data within a selected context closely physically. As emphasized by Renganathan, Li, and Valenzuela (2011), to work with Orang Asli tribe, we need to carry out qualitative-based research whereby we need to work with the community in their settlement Thus, this case study is a form of research that aims to collect information and justify what is happening.

The selection of informants for this study incorporates a Tribes-based purposive sample of six Orang Asli Headman (Tok Batin) or tribal elder aged 30 and older. Six informants were chosen in this study and they ought to be knowledgeable in IKGT and so do their ancient practices. The selection of informants using purposive sampling is based on the idea that researchers wish to explore, learn and perceive, so the informants are observed to enhance the creditability of the findings. Wiersma and Jurs (2005) states that purposive sampling method is used when the aim of the study is targeted on a selected group to obtain the desired information.

The case study involved a semi-structured interview with key informants. Besides, participant observation and document analysis were conducted. Interviews were conducted based on the prepared protocol. The interview protocol is the prime source of case study data. In this study, the interviews were designed to elicit the foremost information and insight from the informants regarding IKGT used by them in environmental sustainability. While conducting the observation, the researcher took part in the study. A digital camera was used to take photographs and record videos in all situations with the permission of the informants. An excursion of the settlement was conducted to notice the plants, handicraft, farms, musical instruments etc and observations were conducted. Document analysis method was used to analyze the data. The researcher thoroughly analyzed the documents generated by the organizations that were enclosed in websites, journals, and books. The accessible and suitable literature was employed in the event of the interview queries that were used to collect the data in this study.

The data collected were processed using Atlas-ti software to ease the organization and composition of the process of coding and classification and also the development of the connection between constructs. The recorded audio was verbatim transcribed and the Malay transcripts were double checked for precision with the records before the interpretation of the data. The transcripts were analyzed using thematic coding approach. According to Boyatzis (1998), thematic analysis is a process for encoding qualitative information that requires an explicit 'code'. The analysis was done by producing theme clusters like (i) IM and (ii) IH. The researcher selected and reviewed the informants' feedback in analyzing these themes. After the themes were analyzed, they were brought along and interpreted in relevance to the purpose of this study.

\section{RESULTS AND DISCUSSION}

A total of 6 informants aged 30 years and older were interviewed in this study. Among them are Tok Batin, TM practitioners, sculpturer, and elderly who are knowledgeable in IKGT and practices of all two themes. The results about the role of Orang Asli IKGT in preserving and sustaining Mother Nature were discussed accordingly based on the two themes as follow. 


\section{IM}

Traditional medicine is well-known in the developing world and its use is spreading like wildfires in the developed countries (Wubetu, Abula, \& Dejenu, 2017). A study conducted by Ullah et al. (2013) states that in third-world regions, medicinal plants are preferred as a mode of treatment for diseases and in many developing countries, bulk of population is dependent upon traditional medicine to meet their principal health care essentials. In this study, the use of IKGT in IM practiced by Orang Asli tribes contributed to the preservation of environmental sustainability which is different from modern medicine. The results revealed that IKGT in IM on plant species as herbal medicine is still stringing in Orang Asli tribes. In the studied settlements, more than $5 \mathrm{IM}$ or treatments were practiced by the subgroups of Mah Meri, Bateq, Semai and Semaq Beri tribes in healing more than 11 disorders using about 10 plant species of medicinal value (Table 1). The recorded species of medicinal plants were Ketum, Orkid, Dukung Anak, Pegaga, Telinga Kera, Durian, Rambutan, Kendur Urat, Bunga Raya, and Tongkat Ali which were culturally defined according to their use of treatments/medicines.

Based on the findings, the plants have been used by the Orang Asli tribes and the elders for the same purpose for a long time starting from the earliest generation to the current generation. Most of the medicinal plants are used in healing common ailments such as fever, cough, and diarrhea. The tribes utilized and maximized the use of medicinal plants for medicinal purpose to heal various health conditions in treating both children and adults from generation to generation as secret family tips. Similarly, a study done by Ullah et al. (2013) found that Orang Asli in Kampung Bawong, Perak is still depending on local plants which include roots, leaves, fruit, branches, flowers and the whole plant as a source of primary medicine and this process of preservation of traditional medicine is seen as an obligation to maintain the continuity of medical resources and culture of human civilization. This is because the traditional medicine practices and healing process are related to their surrounding and spirituality. They believed their diseases or illness were caused by the acts of spiritual punishment, payback, and breaking the rules of their taboos. The majority of the indigenous practitioners and the tribes preferred indigenous healing processes instead of depending on modern medicine provided by the hospitals and rural clinics although they are able to get access to them easily. This is because IM practices and healing process are related to their surrounding and spirituality which help to reconnect them to their legacy, land, cultures and the spirits of their ancestors, bringing the genuine feelings of serenity during their ailment.

TABLE 2. Medicinal plants used for the treatment of various human ailments by the Orang Asli tribe in Malaysia

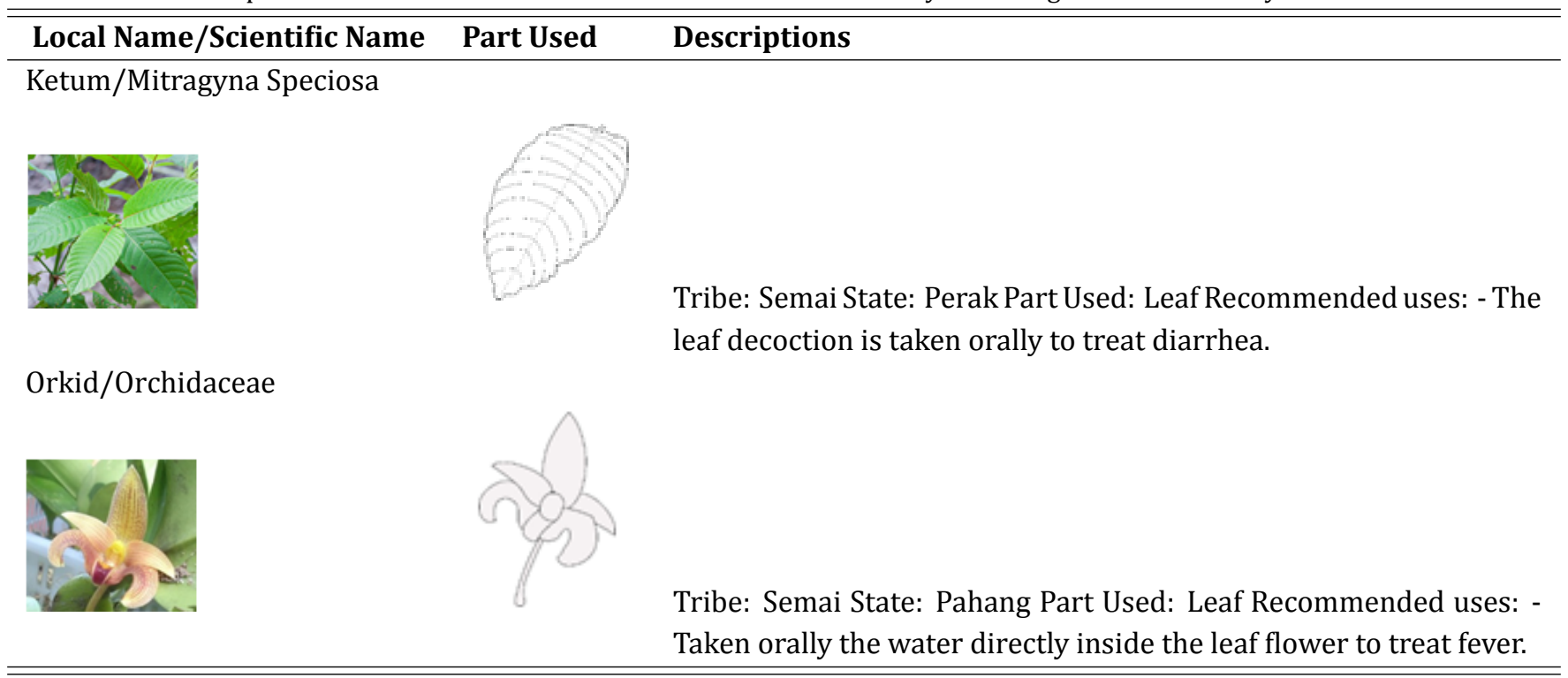

Source: Author's collection and google image 
TABLE 2. Continue... Local Name/Scientific Name

\section{Part Used}

\section{Descriptions}

Tepus/Zingiber Spectabile

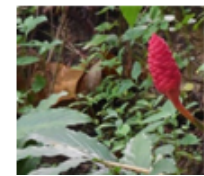

Pegaga/Centella Asiatica

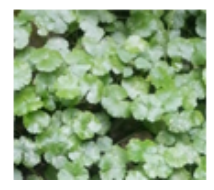

Telinga Kera/Tradescantia

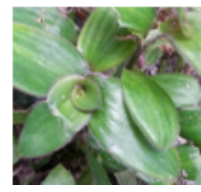

Tongkat Ali/Eurycoma Longifolia

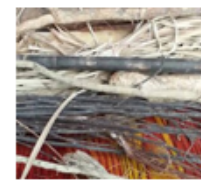

Durian/Durio

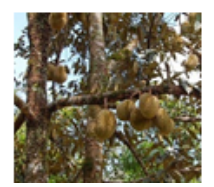

Tribe: Semai State: Pahang Part Used: Red leaf flower Recommended uses: - Red leaf flower decoction is taken orally to add blood.

Tribe: Mah Meri State: Selangor Part Used: Leaf Recommended uses: - The leaf decoction is taken orally to treat fever, relieve pain, headache, and dizziness.

Tribe: Mah Meri State: Selangor Part Used: Leaf Recommended uses: - The leaf decoction is taken orally for healing kidney ailments.

Tribe: Bateq State: Terengganu Part Used: Root Recommended uses: A root decoction is taken orally to refresh the eyes and get rid of thirst.
Tribe: Semaq Beri State: Terengganu Part Used: Root Recommended uses: - Root decoction used for bathing to rejuvenating the body and to treat fever as well as a male tonic. 
TABLE 2. Continue...

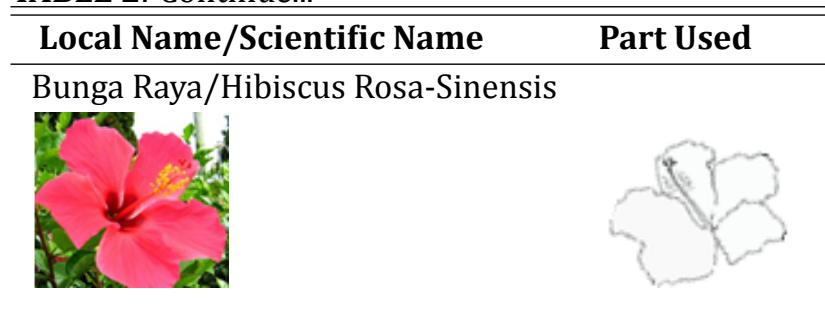

Dukung Anak/Phyllanthus Niruri
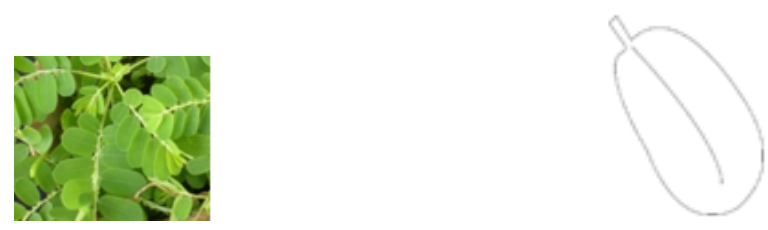

Tribe: Mah Meri State: Selangor Part Used: Leaf \& Root Recommended uses: - Pounded leaves mixed with water, strained and taken orally to treat diarrhea and stomachache. - A root decoction is taken orally to treat jaundice.

Kendur Urat Leaf
Tribe: Semai State: Pahang Part Used: Leaf Recommended uses: The leaf decoction is taken orally to treat diarrhea.
Tribe: Mah Meri State: Selangor Part Used: Leaf Recommended uses: - Leaf decoction used for bathing to treat fever and as a coolant

Source: Author's collection and google image

As stated by Clarke (2008), aboriginal communities put incredible confidence in their own particular healers, who they believe have extraordinary powers derived from their otherworldly ancestors to heal sickness. In addition, they were also concerned that the use of traditional plants and herbs is able to assist them in reducing the use of modern technology. Indeed, the manufacture of modern medicines does contain prohibited substances such as drugs. Due to the simplicity of life, they processed medicinal plant to be used as medicine which does not use modern technology and does not contain chemicals that are harmful to the human body. Unfortunately, it is difficult to find these kinds of medicinal plants in this era of globalization. Similarly, Wubetu et al. (2017) emphasize that there have been no studies conducted in the study area on the use and practice of traditional medicine. The informants emphasized that these plant species grow wildly and can only be found in the jungle. For example, Kendur Urat and other plants are grown in settlement and used by the tribes daily. Not only that, the informants stressed that modern remedies are very expensive and unaffordable compared to IM.

According to Ong and Azliza (2015), the IK in IM is studied and used as a base for finding the novel compounds to treat various diseases. The records of Orang Asli IKGT on medicinal plants with worldwide distribution is a potential agent and represent a helpful beginning stage that can fascinate further researches on novel chemical compounds and po- tentially valuable drugs for present-day medicine to treat different types of ailments (Lambin et al., 2018a). Therefore, it is important for us to sustain, preserve and document the IKGT on IM used by Orang Asli and protect such medicinal important species. Siyanbola et al. (2012) in their study also suggest that there is a need to create a database of information on medicinal plant species used by the study communities, including their methods of application for various ailments. In addition, the preservation of IKGT in IM and medicinal plant resources is to ensure that the transmission of this knowledge taught to young generations is correct and continuously beneficial for future prospective and generations before such knowledge becomes diluted or disappear due to scientific innovation.

\section{IH}

In this study, the result identified that some Orang Asli tribes in Peninsular Malaysia are still depend on forests and local natural sources with subsistence economic activities in their daily life despite present modernization. There are only seven types of handicrafts recorded and found from the tribes of i) Semai located at Raub, Pahang, ii) Mah Meri at Pulau Carey and iii) Temuan which is situated at Rawang, Selangor (Refer to Table 2). Based on the findings of this study, the Mah Meri tribe nominated the IH such as wooden sculptures, shell decorations, craft jewelry, and weaving wall. They managed to preserve a tradition of spiritual woodcarving that is truly world-class in terms of quality 
of its craft and artistry. Hence, they were internationally well-known for their indigenous wood carving skills. In Pahang, the Semai tribes' lifestyles are directly associated with the forest and they possess their own distinctive thoughts on the forest resources. They used weaved bamboo, rattan or Nipah as roof and wall decorations of a house. While the Temuan tribes situated in Selangor also have their own uniqueness and diversities of handicraft that is synonym with the natural environment in terms of the conservation of the sustainability of the environment. For example, the weaving of forest resources used as ceiling or wall decorations and some common household items are the results of the home-based crafts.
In the same vein, several studies have investigated indigenous people's handicraft. A recent study by Islam and Shah (2017) proved the 'Kangri' is a special basket containing chafing earthen pot which is used to counter severe cold during winter by the Kashmiri people. The indigenous people of Arunachal Pradesh, crafting in the Brokpas tribes is exclusively done by the male folk. They collected raw materials such as bamboo, wood, and cane from the forest areas to fulfill its everyday needs. Bora, Paul, Bam, Saikia, and Hazarika (2013) emphasized that the Brokpas tribes are expert craftsmen in making all the items of their daily utility and some common household items are results of their home-based crafts.

TABLE 3. IKGT on IH for sustainability development utilized by the orang asli tribes in Malaysia

\begin{tabular}{|c|c|c|c|}
\hline Tribe/State & Description & & \\
\hline \multirow[t]{2}{*}{ Mah Meri, Selangor } & Wooden Sculpture & & Shell Decoration \\
\hline & Weaving wall/Roof & Hanging Decoration & Craft Jewelry \\
\hline Semai, Pahang & Weaving Wall/Roof & & \\
\hline Temuan, Selangor & Ceiling/Wall Decoration & Bamboo handicraft & \\
\hline
\end{tabular}

Source: Author's collection

Meanwhile, according to Andesmora, Muhadiono, and Hilwan (2017), traditional handicraft such as Jangki (conveyance traditional for women) used as equipment and food in the paddy fields is still in used, nowadays, by some people despite the modern lifestyle. As such, people in Tapa River,
Jambi mostly used Rattan (Calamus marginatus) as handicraft ingredients.

The findings indicated that Orang Asli tribes are very skillful and knowledgeable in recognizing the raw materials of their interest in crafting. As emphasized by Yahaya and Ya- 
haya (2014), the handicrafts produced by Orang Asli tribes possess an artistic value all on their own, and also they are evidently known for inventing unique handicrafts. In this study, the informants stated that their handicrafts are inspired from the nature and surroundings such as bamboo, wood, shell, rattan and other resources which grow wildly and can be collected from the forest or nearby areas of their settlement. Orang Asli tribes use these natural resources because they are easy to get access and at the same time, they are maximizing these sources and avoiding to use of modern sources. They realized the incorporation of a harmful substance in modern sources and thus avoided them since their techniques and main ingredients for making IH is 'GT' which are environmentally-friendly. These tribes were known as the preserver of this culturallyrich important craftsmanship that reflects their beliefs and views of the world which is inherited from their forefathers and have been developed indigenously over a long period. Mostly of the crafted items which have the elements of environmental sustainability are for personal use. Besides, they also utilize all the available natural resources for various purposes of daily utility. This is because in their perspectives and myths, every wooden craft has a different story of the spirit world and this shapes their belief and culture. They have a strong family bond which reaches up to their deceased family members and ancestors who are still worshipped for guidance, goodwill, and well-being (Wahab et al., 2016). Moreover, the tools that they used are also traditional, simple and inexpensive without modern innovation. Indeed, modern technology poses a serious threat to sustainable development due to their harmful effects on natural resources and the environment (Eyong, 2007) which wreaks untold damage to the habitats of wildlife as well. These are speeding the process of biodiversity loss and this problem impacts everyone if environmental degradation and the lessening of resources persist.

\section{CONCLUSION}

All tribes in this study have its own uniqueness and distinctiveness that they inherited from their ancestors. They believed that taboos, the existence of spirits and supernatural will control and give a huge impact in their daily life. Subsequently, they attempted to maximize the use of modern technology to avoid misfortunes and other bad signs in their daily lives if they violate the rules of nature. They did not possess the elaborate technologies that permit them to ignore the nature's own requirements. Thus, they are very cautious and focused on the practice of taboos in their community (Turner et al., 2000). Moreover, they believe that IK and the practice of this heritage exist since the age of their ancestors sometimes ago whereby they were very close to the environment. The close relationship has greatly influenced the way of life and their economic resources (Sam \& Aminah, 2015).

However, there are some weaknesses of the study which may affect the results and conclusion. An expectation of this study is that the informants are knowledgeable about IKGT that has been practiced by them since the days of their ancestors. Informants were expected to know Orang Asli IKGT practices in their daily life. The researcher found that some informants have been more spontaneous in their responses because they are lack of knowledge about 'GT'. Besides that, this study was limited in the geographical aspect as it was only carried out in four states: i. Perak, ii. Selangor, iii. Pahang and iv. Terengganu located in Peninsular Malaysia. Moreover, the study was also limited to five sub-groups of Orang Asli tribes: i. Mah Meri, ii. Semaq Beri, iii. Batek, iv. Semai and v) Temuan. It does not represent the whole tribes of Orang Asli in Peninsular Malaysia. Thus, this study cannot be generalized to overall Orang Asli tribes in Malaysia. More specific information can be obtained by conducting research on the different populations of Orang Asli across the states.

Therefore, it is tremendously important for us to guarantee that IKGT knowledge is not misplaced. It is crucial for us, particularly at the grassroots, to acknowledge and support indigenous knowledge development associated with 'GT' in Malaysia. Mapping and proper documentation of IK is required to preserve and confirm the continuity of "GT" to future generations and the sharing of new knowledge towards using 'GT' identified from the Orang Asli tribes is needed for sustainability development. The co-operation from all respective levels in incorporating indigenous people groups with contrasting knowledge systems is required to secure the Earth's life support systems and to meet the present advancement needs. We must remember that our future generations need this life support system too. There is an urgent need for all community levels over the world to cooperate and collaborate with one another to preserve and sustain the surrounding from worsening in the future.

Not solely that, now it is the right time go back to basic where it is a necessity to apply IKGT and practices used by Orang Asli in their daily life since the days of their ancestors till today. It is additionally necessary to induce a wider view of the tradition and the way Orang Asli IKGT has affected the modern society. Moreover, Orang Asli IKGT is dwindling from the society, and in this case, actions should be taken to preserve the tradition, and something should be 
done to assist the preservation. The preservation of this extraordinary knowledge and the importance of biodiversity conservation is fundamental and the strategies of sustainable use should be reinforced and considered for long-term availability of natural resources here and even in the whole country.

\section{LIMITATIONS AND RECOMMENDATIONS}

The researcher suggested further studies to be carried out involving more target groups of Orang Asli tribes throughout Malaysia to increase the reliability and validity of the study results. It would be interesting to identify IKGT of the native at Sabah and Sarawak. In addition to that, research related to the aspect of $\mathrm{IH}$ should be studied in a deeper manner. Apart from that, the triangulation of qualitative and quantitative approaches is recommended to enhance the research methodology on Orang Asli IKGT. The researcher also suggested studying the level of awareness of Orang Asli with appropriate approaches to attract the interest of the younger generation in learning and inheriting IKGT. Orang Asli IKGT of IM and IH for sustainable development need to be taught to young generations for the continued survival on the Earth and this will help to conserve and preserve the cultural heritage of Orang Asli tribes of Peninsular Malaysia at large. This is because these tribes are known as the preserver that reflects their beliefs and views of the world which were inherited from their forefathers and have developed indigenously over a long period.

\section{REFERENCES}

Abdul Ghani Azmi, I. M. (2017). Voices from the dead: The uneasy case of indigenous cultural expression. International Journal of Law and Management, 59(4), 522-533. doi:https://doi.org/10.1108/ijlma-03-2016-0027

Ahmad, B., Khalid, B. A. K., Quek, K. F., Zaini, A., \& Phipps, M. E. (2013). Knowledge of diabetes and lifestyle behaviour amongst indigenous population in peninsular Malaysia. Medical Journal Malaysia, 68(4), 309-315. doi:https://doi .org/10.1016/j.diabres.2011.02.020

Ajibade, L. (2003). Methodology for the collection and evaluation of farmer's indigenous environmental knowledge in developing countries. African Journal of Indigenous Knowledge Systems, 2(3), 99-113. doi:https://doi.org/10.4314/ indilinga.v2i1.47002

Andesmora, E. V., Muhadiono, \& Hilwan, I. (2017). Ethnobotanical study of plants used by people in hiang indigenous Forest Kerinci, Jambi. The Journal of Tropical Life Science, 7(2), 95-101. doi:http://doi.org/10.11594/Jtls.07.02.02

Ang, K. C., Leow, J. W. H., Yeap, W. K., Hood, S., Mahani, C., M., \& Md-Zain, B. M. (2011). Phylogenetic relationships of the orang asli and iban of Malaysia based on maternal markers. Genetics And Molecular Research, 10(2), 640-649. doi:https:// doi.org/10.4238/vol10-2gmr1011

Augare, H. J., David-Chavez, D. M., Groenke, F. I., Plume-Weatherwax, M. L., Fight, L. L., Meier, G., \& Valdez, S. (2017). A cross methodology for the collection and evaluation of farmer's indigenous environmental knowledge in developing countries. African Journal of Indigenous Knowledge Systems, 2(5), 99-113.

Baer, A. S. (1999). Health, disease, and survival: A biomedical and genetic analysis of the orang asli of Malaysia. Center For Orang Asli Concerns., 30(2), 02-390. doi:https://doi.org/10.1017/s0022463400013321

Bellwood, P. (1997). Prehistory of the Indo-Malaysian archipelago Honolulu. Hawaii, HI: University of Hawaii Press.

Bloemfontein, H. (2009). The incorporation of indigenous knowledge in land maghah josephine akenji reform projects: The basotho letjhabile and maolosi trust agricultural projects (Unpublised master's thesis). University of The Free State, Bloemfontein, South Africa.

Bora, L., Paul, V., Bam, J., Saikia, A., \& Hazarika, D. (2013). Handicraft skills of yak pastoralists in arunachal pradesh. Indian Journal of Traditional Knowledge, 2(1), 25-40.

Boyatzis, R. E. (1998). Transforming qualitative information: Thematic analysis and code development. New York, NY: Sage.

Boyer, Y. (2011). First nations, metis and inuit health and the law: A framework for the future (Unpublished doctoral dissertation). University of Ottawa, Ottawa, Canada.

Carey, I. (1976). Orang asli: The aboriginal tribes of peninsular Malaysia. Oxord, UK: Oxford University Press.

Cherdchoongam, S., \& Rungreunganun, V. (2015.). An application of analytical hierarchy process for ranking factors affecting of thai natural rubber ribbed smoked sheets no.3 (rss3) price. International Journal of Technology and Engineering Studies, 1(2), 42-47. doi:https://doi.org/10.20469/ijtes.40002-2

Clarke, P. A. (2008). Aboriginal healing practices and Australian bush medicine. Journal of the Anthropological Society of South Australia, 33(1), 3-38. 
Dentan, R. K. (1968). The semai: A nonviolent people of Malaya. New York, NY: Holt McDougal.

Ebele, N., Anyaoku, N., Orizu, O. E., \& Eneh, E. A. (2015). Collection and preservation of traditional medical knowledge: Roles for medical libraries in Nigeria. Journal Of Library And Information Sciences, 3(1), 33-43. doi:https://doi.org/ $10.15640 /$ jlis.v3n1a2

Edo, J., \& Fadzil, K. S. (2004). Socio-economic adjustments of the aborigines: Malaysia. In An Internationa Seminar on Multidisciplinary Discourse, Jointly Organized By Fo Guang University, Selangor, Malaysia.

Eyong, C. T. (2007). Indigenous knowledge and sustainable development in Africa. Central African Jourbal, 1(2), 121-139.

Eyong, C. T., Mufuaya, M., \& Foy, I. I. (2004). Literature and culture-the sustainability connection from an African perspective. Regional Sustainable Development Review, 1(2), 1-13.

Frid, A., McGreer, M., Haggarty, D. R., Beaumont, J., \& Gregr, E. J. (2016). Rockfish size and age the crossroads of spatial protection, central place fisheries, and indigenous rights. Global Ecology and Conservation, 8(3), 170-182. doi:https:// doi.org/10.1016/j.gecco.2016.09.008

Fui, L. H. (1997). Orang asli, forest, and development. Serdang, Malayisa: Forest Institute Malaysia.

Government Treasury. (2017). Kementerian tenaga, teknologi hijau dan air, ke ttha malaysia,. dasar teknologi hijau negara. kettha. Retrieved from https://bit.1y/2D1ZJaa (accessed on 15 August, 2018)

Green Technology. (2015). 3 ways activist kids these days resemble their predecessors. Retrieved from https://bit. Iy/ 2TXLMQc (accessed on 14 July, 2017)

Hamid, H., Samah, A. A., \& Man, N. (2013). The level of perceptions toward agriculture land development programme among orang asli in pahang, Malaysia. Asian Social Science, 9(10), 151. doi:https://doi.org/10.5539/ass.v9n10p151

Hong, E. (1987). Natives of sarawak: Survival in borneo's vanishing forest. Selangor, Malaysia: Institut Masyarakat.

Hood, S. (2006). People and tradition the orang asli: Origins, identity and classification. New York, NK: Archipelago Press.

International Work Group For Indigenous Affairs. (2017). Indigenous peoples in Malaysia. Retrieved from https ://bit. Iy/ 2Iq3ERR (accessed on 8 August, 2018)

Islam, M. A., \& Shah, S. S. G. (2017). Traditional wicker handicraft by the shaakhsaazi communities of rural Kashmir. International Journal of Teaching and Knowledge, 1(10), 23-50.

Ismail, E., Amini, F., Razak, S. A., Zaini, H. M., Farhour, R., \& Zilfafalil, B. A. (2013). Peninsular Malaysia's negrito orang asli and its theory of African origin. Sains Malaysiana, 42(7), 921-926.

Jabatan Kemajuan Orang Asli Malaysia. (2017). Jabatan hal ehwal orang asli report of 2017. Retrieved from https:// bit.1y/2IhVryY (accessed on 10 August, 2018)

Lambin, R., Wahab, N. A., Choo, G. S., Mustapha, R., \& Abdullah. (2018b). A case study of orang asli indigenous knowledge in traditional medicine. International Journal of Academic Research in Business and Social Sciences, 8(4), 998-1010. doi:http://dx.doi.org/10.6007/IJARBSS/v8-i4/4127

Lambin, R., Wahab, N. A., Choo, G. S., Mustapha, R., \& Abdullah, R. (2018a). A case study of orang asli indigenous knowledge in traditional medicine. International Journal of Academic Research in Business and Social Sciences, 8(4), 998-1010.

Lee, J. H., Kim, S. P., \& Jeon, R. W. (2016). Optimal design for adiabatic pipes using vacuum at cryogenic temperatures. Journal of Advances in Technology and Engineering Research, 2(2), 6-11. doi:https://doi.org/10.20474/-jater2.1.2

Lim, A. A. K., H.F., Mukrimah, A., Norliyana, A., \& Intan, N. B. (2017). Transmission of oral traditions among the indigenous temuan community in peninsular Malaysia. In 10 International Conference on Traditional Forest, Slenger, Malaysia.

Macherera, M., Chimbari, M. J., \& Mukaratirwa, S. (2017). Indigenous environmental indicators for malaria: A district study in Zimbabwe. Acta Tropica, 175(12), 50-59. doi:https://doi.org/10.1016/j.actatropica.2016.08.021

Makkar, H. (2013). Green telecom layered framework for calculating carbon footprint of telecom network. International Journal of Research In Engineering and Technology, 2(9), 425-431. doi:https://doi.org/10.15623/ijret.2013.0209064

Masron, T., Masami, F., \& Ismail, N. (2013). Orang asli in peninsular Malaysia: Population, spatial distribution and socioeconomic condition. Journal Ritsumeikan Social Science Humanity, 6(5), 75-115.

Melchias, G. (2001). Biodiversity and conservation. New Dehli, India: Enfield Science Publishers.

Mustapha, R., Omar, M., Hassan, S. N. S., Yasin, R. M., \& Salleh, N. M. (2010). Human capital development of orang asli youth: Supportive and suppressive factors. Procedia-Social and Behavioral Sciences, 7, 592-600. doi:https://doi.org/ 10.1016/j.sbspro.2010.10.080 
Nakata, M., Byrne, N. V., A., \& Gardiner, G. (2005). Indigenous knowledge, the library and information service sector, and protocols. Australian Academic and Research Libraries, 36(2), 7-21. doi:Http://Doi.Org/10.1080/00048623.2005 .10721244

National Aeronautics and Space Administration. (2018). Global temperature. Retrieved from https://go.nasa.gov/ $2 \mathrm{mjzvJu}$ (accessed on 11 August, 2018)

Ndangwa, N. (2007). Indigenous education systems and their relevance for sustainable development: A case of Southern Africa. Environment and Sustainable Development, 1(1), 167-172.

Nicholas, C. (1996). The orang asli of peninsular Malaysia. New York, NY: John and Willy.

Norizan, H., Hussin, S., \& Hasimah, A. R. (2017). Peranan aplikasi teknologi hijau dalam konteks melestarikan alam sekitar menurut perspektif Islam. E-Jurnal Penyelidikan Dan Inovasi, 4(1), 1-12.

Ong, H., \& Azliza, M. (2015). Medicinal plants for diabetes by the orang asli in Selangor, Malaysia. Studies on Ethno-Medicine, 9(1), 77-84. doi:https://doi.org/10.1080/09735070.2015.11905423

Ong, H., Faezah, A., \& Milow, P. (2012). Medicinal plants used by the jah hut orang asli at kampung pos penderas, Pahang, Malaysia. Studies on Ethno-Medicine, 6(1), 11-15. doi:https://doi.org/10.1080/09735070.2012.11886414

Parsons, M., Nalau, J., \& Fisher, K. (2017). Alternative perspectives on sustainability: Indigenous knowledge and methodologies. Challenges in Sustainability, 5(1), 7-14. doi:https://doi.org/10.12924/cis2017.05010007

Poe, M. R., Norman, K. C., \& Levin, P. S. (2014). Cultural dimensions of socioecological systems: Key connections and guiding principles for conservation in coastal environments. Conservation Letters, 7(3), 66-175. doi:https://doi.org/10.1111/ conl.12068

Ramlee, M. (2013). Attributes that affect self-efficacy and career development of orang asli youth in Peninsular Malaysia. Journal of Southeast Asian Education, 1(1), 23-40.

Renganathan, S., Li, C. S., \& Valenzuela, J. (2011). Living literacies the orang asli literacy project. Arts and Social Sciences Journal, 1(5), 27-40.

Robinson, J. B., \& Herbert, D. (2001). Integrating climate change and sustainable development. International Journal of Global Environmental Issues, 1(2), 130-149. doi:https://doi.org/10.1504/ijgenvi.2001.000974

Sam, M., \& Aminah, S. (2015). Kajian amalan budaya orang asli suku kaum jakun di kampung peta (Unpublished doctoral dissertation). Universiti Tun Hussein Onn Malaysia, Parit Raja, Malaysia.

Sangha, K. K., Le Brocque, A., Costanza, R., \& Cadet-James, Y. (2015). Ecosystems and indigenous well-being: An integrated framework. Global Ecology and Conservation, 4(1), 197-206. doi:https://doi.org/10.1016/j.gecco.2015.06.008

Siyanbola, W. O., Egbetokun, O. I., A. A., Olamade, O. O., Aderemi, H. O., \& Sanni, M. (2012). Indigenous technologies and innovation in Nigeria : Opportunities for smes. American Journal of Industrial and Business Management, 2(2), 64-75. doi:https://doi.org/10.4236/ajibm.2012.22009

Thevakumar, K., Chandren, J. R., Perez-Perez, I., G., Chua, E. G., Teh, L. K., ... Wong, L. P. (2016). Assessment of risk and sero-prevalence of helicobacter pylori colonization among remote orang asli tribes in peninsula Malaysia. Plos One, 11(7). doi:https://doi.org/10.1371/journal.pone.0159830

Turner, N. J., Ignace, M. B., \& Ignace, R. (2000). Traditional ecological knowledge and wisdom of aboriginal peoples in British Columbia. Ecological applications, 10(5), 1275-1287. doi:https://doi.org/10.1890/1051-0761(2000)010[1275: tekawo]2.0.co;2

Ullah, M., Khan, M. U., Mahmood, A., Malik, R. N., Hussain, M., Wazir, S. M., \& Shinwari, Z. K. (2013). An ethnobotanical survey of indigenous medicinal plants in wana district South Waziristan agency, Pakistan. Journal of Ethnopharmacology, 150(3), 918-924. doi:https://doi.org/10.1016/j.jep.2013.09.032

United Nation. (2007). Bridging the gap: Policies and practises on indigenous peoples' natural resource management in Asia. Retrieved from https://bit.1y/2WJ1Qc0 (accessed on 14 July, 2018)

Victoria, J., Mahayuddin, A., S., Zaharuddin, W. A. Z. W., H., N., S., \& Ismail, B. (2017). Bioclimatic design approach in dayak traditional longhouse. Procedia Engineering, 180(12), 562-570. doi:https://doi.org/10.1016/j.proeng.2017.04.215

Wahab, N. A., Mustapha, R. B., \& Ahmad, A. R. (2016). The roles of administrators in aboriginal schools: A case study in a Malaysian state. International Journal of Social Science And Humanity, 6(5), 370-374. doi:https://doi.org/10.7763/ ijssh.2016.v6.674

Wiersma, W., \& Jurs, S. G. (2005). Research methods in education. New York NY: John and Willy Son. 
Wubetu, M., Abula, T., \& Dejenu, G. (2017). Ethnopharmacologic survey of medicinal plants used to treat human diseases by traditional medical practitioners in dega damot district, Amhara, Northwestern Ethiopia. BMC Research Notes, 10(1), 157-167. doi:https://doi.org/10.1186/s13104-017-2482-3

Yahaya, F. H., \& Yahaya, L. S. (2014). The empowerment of orang asli women in the tourism industry in lenggong, perak. In High School Conference, New York, NY.

Zainal, Z. (2007). Case study as a research method. Jurnal Kemanusiaan, 9(2), 1-6. 